Louisiana State University

LSU Digital Commons

Faculty Publications

Department of Biological Sciences

$6-1-2020$

\title{
Altered gut microbiota in infants is associated with respiratory syncytial virus disease severity
}

\author{
Jeffrey N. Harding \\ Louisiana State University \\ David Siefker \\ Louisiana State University \\ Luan $\mathrm{Vu}$ \\ Louisiana State University \\ Dahui You \\ University of Tennessee Health Science Center \\ John Devincenzo \\ University of Tennessee Health Science Center
}

See next page for additional authors

Follow this and additional works at: https://digitalcommons.Isu.edu/biosci_pubs

\section{Recommended Citation}

Harding, J., Siefker, D., Vu, L., You, D., Devincenzo, J., Pierre, J., \& Cormier, S. (2020). Altered gut microbiota in infants is associated with respiratory syncytial virus disease severity. BMC Microbiology, 20 (1) https://doi.org/10.1186/s12866-020-01816-5

This Article is brought to you for free and open access by the Department of Biological Sciences at LSU Digital Commons. It has been accepted for inclusion in Faculty Publications by an authorized administrator of LSU Digital Commons. For more information, please contact ir@lsu.edu. 
Authors

Jeffrey N. Harding, David Siefker, Luan Vu, Dahui You, John Devincenzo, J. F. Pierre, and Stephania A. Cormier 


\title{
Altered gut microbiota in infants is associated with respiratory syncytial virus disease severity
}

Jeffrey N. Harding 1,2, David Siefker ${ }^{1,2}$, Luan Vu',2, Dahui You ${ }^{3,4}$, John DeVincenzo ${ }^{3,4}$, JF. Pierre ${ }^{3,4}$ and Stephania A. Cormier ${ }^{1,2^{*}}$ (D)

\begin{abstract}
Background: Respiratory syncytial virus (RSV) is the number one cause of lower respiratory tract infections in infants. There are still no vaccines or specific antiviral therapies against RSV, mainly due to the inadequate understanding of RSV pathogenesis. Recent data suggest a role for gut microbiota community structure in determining RSV disease severity. Our objective was to determine the gut microbial profile associated with severe RSV patients, which could be used to help identify at-risk patients and develop therapeutically protective microbial assemblages that may stimulate immuno-protection.

Results: We enrolled 95 infants from Le Bonheur during the 2014 to 2016 RSV season. Of these, 37 were wellbabies and 58 were hospitalized with RSV. Of the RSV infected babies, 53 remained in the pediatric ward (moderate) and 5 were moved to the pediatric intensive care unit at a later date (severe). Stool samples were collected within $72 \mathrm{~h}$ of admission; and the composition of gut microbiota was evaluated via $16 \mathrm{~S}$ sequencing of fecal DNA. There was a significant enrichment in S24_7, Clostridiales, Odoribacteraceae, Lactobacillaceae, and Actinomyces in RSV (moderate and severe) vs. controls. Patients with severe RSV disease had slightly lower alpha diversity (richness and evenness of the bacterial community) of the gut microbiota compared to patients with moderate RSV and healthy controls. Beta diversity (overall microbial composition) was significantly different between all RSV patients (moderate and severe) compared to controls and had significant microbial composition separating all three groups (control, moderate RSV, and severe RSV).
\end{abstract}

Conclusions: Collectively, these data demonstrate that a unique gut microbial profile is associated with RSV disease and with severe RSV disease with admission to the pediatric intensive care unit. More mechanistic experiments are needed to determine whether the differences observed in gut microbiota are the cause or consequences of severe RSV disease.

Keywords: Respiratory syncytial virus, Human, Gut microbiome, 16S, Microbiota, Infants, Severity

\footnotetext{
* Correspondence: stephaniacormier@lsu.edu

'Department of Biological Sciences, Louisiana State University, 202 Life

Sciences Building, Baton Rouge, LA 70803, USA

${ }^{2}$ Department of Comparative Biomedical Sciences, Louisiana State University

School of Veterinary Medicine, Baton Rouge, LA, USA

Full list of author information is available at the end of the article
}

(c) The Author(s). 2020 Open Access This article is licensed under a Creative Commons Attribution 4.0 International License, which permits use, sharing, adaptation, distribution and reproduction in any medium or format, as long as you give appropriate credit to the original author(s) and the source, provide a link to the Creative Commons licence, and indicate if changes were made. The images or other third party material in this article are included in the article's Creative Commons licence, unless indicated otherwise in a credit line to the material. If material is not included in the article's Creative Commons licence and your intended use is not permitted by statutory regulation or exceeds the permitted use, you will need to obtain permission directly from the copyright holder. To view a copy of this licence, visit http://creativecommons.org/licenses/by/4.0/ The Creative Commons Public Domain Dedication waiver (http://creativecommons.org/publicdomain/zero/1.0/) applies to the data made available in this article, unless otherwise stated in a credit line to the data. 


\section{Background}

Respiratory syncytial virus (RSV) is a ubiquitous respiratory virus infecting the majority of the human population by 1 year of age [1]. While most infants develop mild upper respiratory tract infections (URTI), $0.5-2 \%$ develop severe, lower respiratory tract infections (LRTI), including bronchiolitis and pneumonia, requiring hospitalization [2]. Each year, RSV causes 33 million cases and 3.4 million hospitalizations worldwide in children under 5 years of age [3]. In the U.S. alone, RSV causes 85,000 to 144,000 hospitalizations [4], 14,000 deaths [2], and $\sim 2.6$ billion in medical care costs each year [5]. Despite the substantial RSV-associated medical and economic burden worldwide, a vaccine for RSV currently remains elusive. The only prevention for infants at high-risk for complications (i.e., premature or underlying immune/cardiopulmonary diseases) is in the form of a monoclonal antibody, palivizumab. In view of the fact that RSV is a "significant unmet medical need" [6] with no known vaccine, there is a necessity to find therapeutic approaches to prevent and treat severe RSV infections.

The recently discovered relationship between respiratory health and gut microbiome dysbiosis has attracted growing interest for therapeutic manipulation to improve vaccine effectiveness and to allow for alternative therapies for viruses with no known vaccines, like RSV. Clinical studies demonstrate that prebiotic and probiotic supplementation alters gut microbiota [7], reduces the incidence of rhinovirus infections in preterm infants [8], and reduces rhinovirus infection duration and severity in adults [9]. In mice, gut microbial dysbiosis induced by antibiotic treatment inhibits pulmonary type I interferons (IFNs) and $\mathrm{T}$ cell responses, resulting in increased lung viral loads after infection with influenza virus $[10,11]$. On the other hand, supplementing mice with Lactobacillus plantarum promotes type I IFNs and reduces influenza viral load in the lung [12]. In mice, both RSV and influenza virus infection alters the gut microbiome and provides preferential growth environments for the $S 24+7$ family showing a correlation between $S 24 \_7$ family and RSV infection, although the mechanism is still unknown [13]. Several reports have studied the association of airway microbiota with RSV severity [14, 15]; nevertheless, there have been no studies that directly investigated the role of gut microbiota in the severity of RSV infections.

We hypothesize that gut microbiota could play an essential role in the pathogenesis of RSV in infants. This study characterizes the gut microbiome in infants hospitalized with RSV infection differentiating severe infections requiring infants to be put into pediatric intensive care unit (PICU) and moderate infections of infants in the general ward. Our results demonstrate that there is a relationship between RSV infection and gut microbiome that could conceivably be interrogated to develop a useful therapeutic target to prevent severe RSV disease.

\section{Results}

\section{Characteristics of study population}

Our study population included 37 patients enrolled from Le Bonheur Outpatient Clinic during well-baby checkup (control) and 58 patients admitted to the general ward (moderate), who tested positive for RSV and negative for influenza by RT-PCR. Samples were collected from patients during the 2014 to 2016 RSV seasons. Subsequent to enrollment, 5 patients were moved from the general ward to the pediatric intensive care unit (PICU). These patients were classified as severe. None of the enrolled patients received antibiotics prior to sample collection. Control, moderate, and severe patients had an average age of 93,94 , and 60 days, respectively $(p=0.284$; Table 1). The majority of moderate and severe patients had $\mathrm{O} 2$ supplementation $(p=<0.001)$ and wheezing $(p=0.011)$ compared to the control group. From patient enrollment forms, there were no significant differences in the average time of symptom onset in moderate patients (6.82 days) compared to severe patients (7.33 days). As both wheezing and $\mathrm{O} 2$ supplementation is commonly associated with RSV, this correlation is not surprising. However, the only significant difference observed between the RSV groups (moderate and severe) regarding all demographic metadata was in the family history of asthma due to none of the severe patients having a family history of asthma (Table 1).

\section{The gut microbiome}

Although the role of gut microbiota in regulating the immune system and respiratory infections is being increasingly recognized, the role of gut microbiota in RSV disease severity has never been addressed in infant humans. Here, we analyzed the gut microbiota from infants hospitalized with RSV. The patient fecal DNA was isolated for microbiome analysis by $16 \mathrm{~S}$ rRNA sequencing (Fig. 1a). Resulting sequencing data was analyzed using Qiime 2 pipeline with a 99\% OTU identification by GreenGenes database (Fig. 1b).

\section{Gut microbiome richness is reduced in severe RSV infected patients}

To examine the gut microbiota in RSV patients, we determined the $\alpha$-diversity in the stool samples using Chao1 index and Shannon index in QIIME 2 with samples rarefied to a read depth of 6682 to ensure that a reasonable number of sequence reads have been obtained for each OTU (Supplemental Figure 1A). There was no difference in the species richness and evenness ( $\alpha$-diversity) of gut microbiome between RSV patients and control patients (Fig. 2a, b). We further segregated the RSV patients into moderate and severe RSV patients (based on their PICU status) to determine if there are differences in gut microbiome as a result of severity of 
Table 1. Participant characteristics of healthy controls and infants hospitalized with RSV

\begin{tabular}{|c|c|c|c|c|c|c|c|}
\hline \multirow[b]{2}{*}{ Characteristic } & \multicolumn{4}{|c|}{ RSV } & \multirow[b]{2}{*}{ severe RSV } & \multirow{3}{*}{$\begin{array}{c}\text { P - value } \\
\text { (RSV vs control) } \\
0.407\end{array}$} & \multirow{3}{*}{$\begin{array}{c}\mathrm{P} \text { - value } \\
\text { (moderate RSV vs severe RSV) } \\
0.999\end{array}$} \\
\hline & & control & (moderate and severe) & moderate RSV & & & \\
\hline \multirow[t]{2}{*}{ Sex - No (\%) } & Male & $17(45.9 \%)$ & $32(55.2 \%)$ & $29(54.7 \%)$ & $3(60.0 \%)$ & & \\
\hline & Female & $20(54.1 \%)$ & $26(44.8 \%)$ & $24(45.3 \%)$ & $2(40.0 \%)$ & & \\
\hline Age (d) \pm SD & & $93 \pm 97.2$ & $91.1 \pm 70.7$ & $94 \pm 73$ & $59.6 \pm 23.5$ & 0.284 & 0.362 \\
\hline \multirow[t]{3}{*}{ Race - No(\%) } & Caucasian & $6(16.2 \%)$ & $19(32.8 \%)$ & $16(39.2 \%)$ & $3(60.0 \%)$ & 0.200 & 0.391 \\
\hline & $\begin{array}{l}\text { African- } \\
\text { American }\end{array}$ & $30(81.1 \%)$ & $38(65.5 \%)$ & $36(67.9 \%)$ & $2(40.0 \%)$ & & \\
\hline & Other & $1(2.7 \%)$ & $1(1.7 \%)$ & $1(1.9 \%)$ & $0(0.0 \%)$ & & \\
\hline Gestational age (wks) \pm SD & & $38.9 \pm 1.4$ & $37.3 \pm 2.9$ & $37.4 \pm 3.0$ & $35.8 \pm 2.5$ & 0.004 & 0.097 \\
\hline Birth weight (g) (mean) \pm SD & & $3,140 \pm 504$ & $2898 \pm 982$ & $2,927 \pm 994$ & $2586 \pm 860$ & 0.345 & 0.398 \\
\hline $\mathrm{O}_{2}$ supplementation (\%) & & $0(0.0 \%)$ & $47(81.0 \%)$ & $42(79.2 \%)$ & $5(100 \%)$ & $<0.001$ & 0.572 \\
\hline $\begin{array}{l}\text { Family History of Asthma } \\
(\%)\end{array}$ & & $15(40.5 \%)$ & $30(51.7 \%)$ & $30(56.6 \%)$ & $0(0.0 \%)$ & 0.399 & 0.021 \\
\hline $\begin{array}{l}\text { Patient history } \\
\text { of wheezing (\%) }\end{array}$ & & $0(0.0 \%)$ & $9(15.5 \%)$ & $8(15.1 \%)$ & $1(20.0 \%)$ & 0.011 & 0.584 \\
\hline Exposure to tobacco (\%) & & $5(13.5 \%)$ & $13(22.4 \%)$ & $12(22.6 \%)$ & $1(20.0 \%)$ & 0.421 & 0.999 \\
\hline Pets (\%) & & $7(18.9 \%)$ & $23(39.7 \%)$ & $21(39.6 \%)$ & $2(40.0 \%)$ & 0.045 & 0.999 \\
\hline \multirow[t]{2}{*}{ Delivery mode - No (\%) } & Vaginal & $24(64.9 \%)$ & $27(46.6 \%)$ & $25(45.9 \%)$ & $2(40.0 \%)$ & 0.095 & 0.999 \\
\hline & C-section & $13(35.1 \%)$ & $31(53.5 \%)$ & $28(54.1 \%)$ & $3(60.0 \%)$ & & \\
\hline \multirow[t]{3}{*}{ Food source } & Breast milk & $24(64.9 \%)$ & $25(43.1 \%)$ & $22(42.6 \%)$ & $3(60.0 \%)$ & 0.187 & 0.678 \\
\hline & Formula & $27(73.0 \%)$ & $48(82.8 \%)$ & $43(82.0 \%)$ & $5(100 \%)$ & & \\
\hline & Solid food & $8(21.6 \%)$ & $6(10.3 \%)$ & $6(11.5 \%)$ & $0(0.0 \%)$ & & \\
\hline
\end{tabular}

$P$ values in the table were calculated using Fisher's Exact test

A.
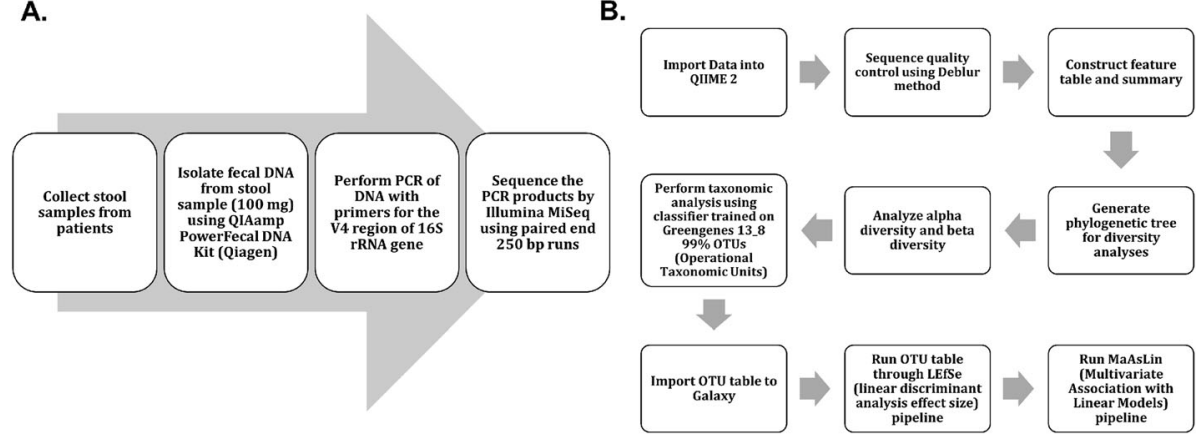

Fig. 1 Sample collection process and data analysis workflow. a Workflow from sample collection to sequence data. b Data analysis workflow in Qiime 2 and Galaxy 

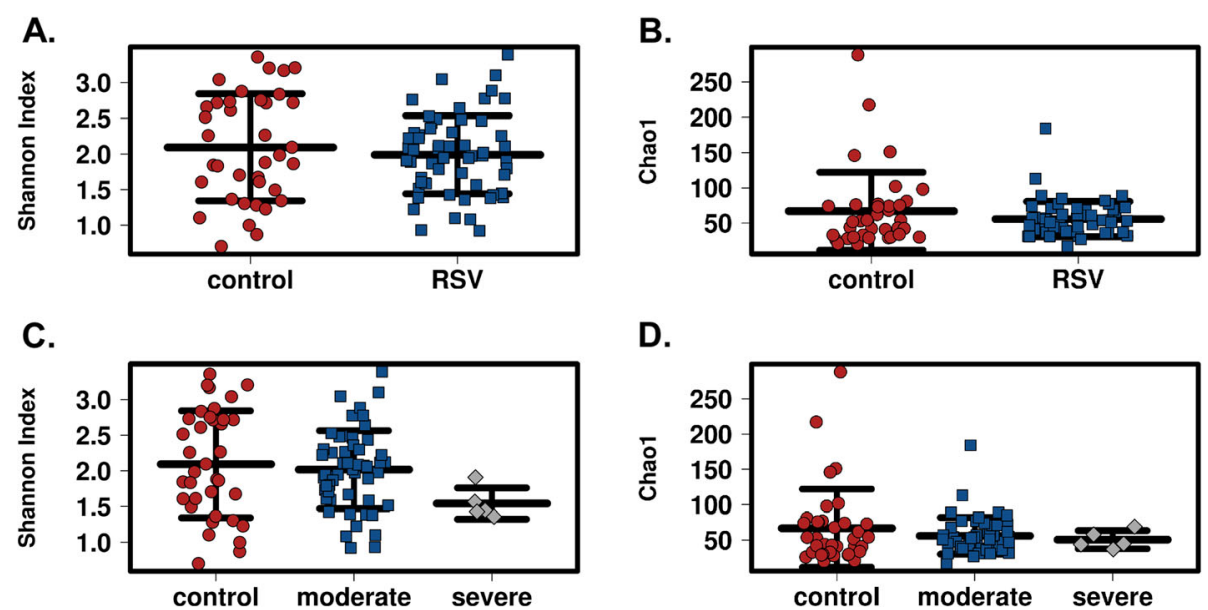

D.

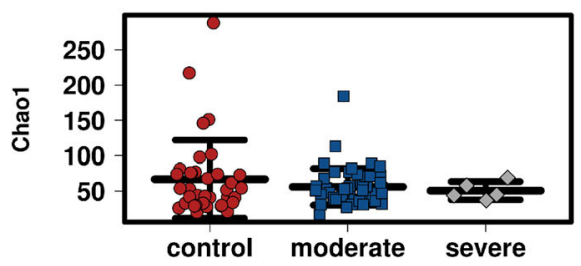

Fig. 2 a-diversity is not significantly reduced in severe RSV infected patients compared to healthy controls. a Shannon Index of the gut microbiota shows no difference between healthy controls $(n=37)$ and infants with RSV disease $(n=58)$. $\mathbf{b}$ Chao 1 Index of the gut microbiota shows no difference between healthy controls $(n=37)$ and infants with RSV disease $(n=58)$. c Shannon Index is slightly reduced in severe RSV disease $(n=5)$ compared to healthy controls $(n=37)$ or infants with moderate RSV disease $(n=53)$ but is not significant. d Chao 1 Index shows no difference in severe RSV disease $(n=5)$ compared to healthy controls $(n=37)$ and infants with moderate RSV disease $(n=53)$. Each point represents an individual infant and the mean \pm SEM

RSV disease. Although it failed to reach significance, patients with severe RSV (PICU) had a slightly reduced species richness and evenness in the gut microbiota compared to that of control and moderate RSV (nonPICU) patients using both Shannon index and Chao1 index (Fig. 2c, d).

Gut microbiome phylogenetic diversity shows significant clustered populations in RSV disease severity

In addition to richness and evenness of gut microbiota, we determined the overall qualitative relatedness of phylogenetic distances ( $\beta$-diversity). Significant differences were found in microbiome composition between RSV and control group as well as between RSV disease severities. We applied the multivariate method of PERMANOVA with 999 permutations using unweighted and weighted UniFrac distance matrix $(P<0.0001$ and $P=$ 0.031 , respectively). In addition, we used multivariate redundant discriminant analysis (RDA) at the OTU level to visualize the separation of RSV and the control groups (Fig. 3a). The patients were further distinguished into groups by disease severity (Fig. 3b). This showed
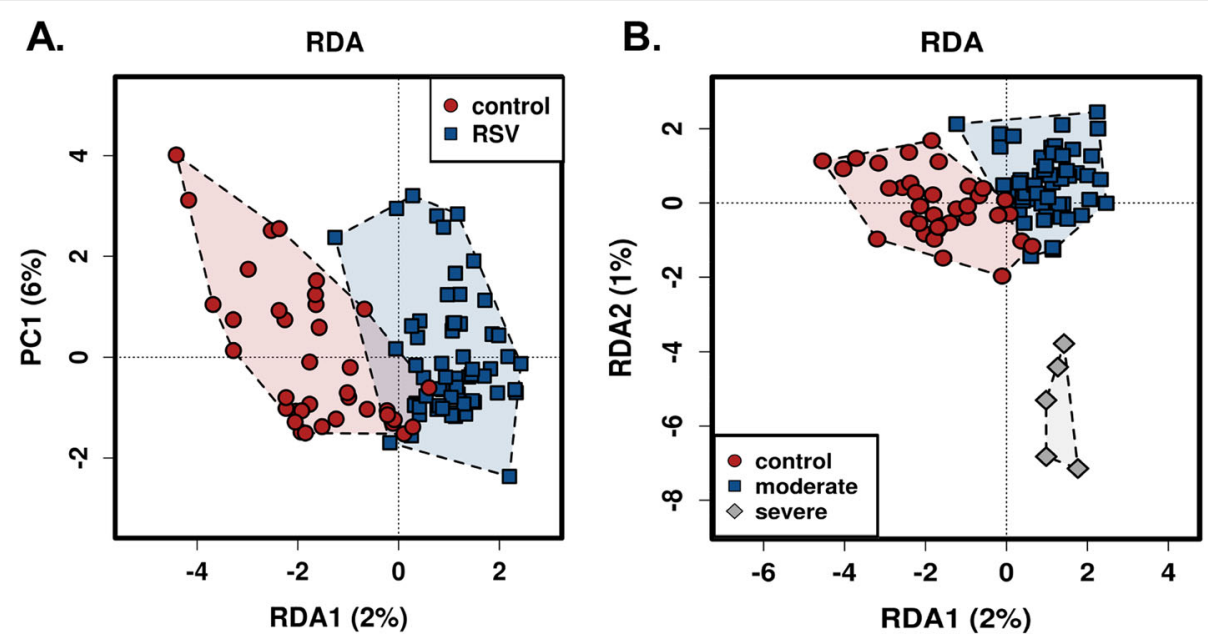

Fig. 3 RDA plots show separate phylogenetic clustering for control and RSV patients. Gut microbiome composition in infants infected with RSV and healthy control infants were analyzed using RDA to visualize the phylogenetic dissociations in RSV infected patients compared to healthy controls. a Control patients cluster separately from moderate or severe RSV patients on a phylogenetic basis. b Severe RSV patients cluster separately from control and moderate RSV patients showing a significantly different phylogenetic composition 
that there were not only statistically significant differences between the control and RSV patients, but there was a further separation between severity of RSV in the patients $(P<0.05)$. To expand our understanding of the phylogenetic differences driving the separation of clusters, we performed Linear Discriminate Analysis of Effect size (LEfSe) analysis to identify enriched taxa that best characterize the alterations in the severe, moderate, and control patients by coupling standard tests for statistical significance and biological relevance through prior knowledge stored in databases such as KEGG, SEED, COGs, etc.. We were able to identify the key phylotypes that could be used as biomarkers at different phylogenetic levels to discriminate between control, moderate, and severe RSV (Fig. 4; Supplemental Figures 2 and 3). LEfSe comparison of the gut microbiota highlights the distinctive microbial profile of patients with severe disease. The taxa in gray show the specific microbial groups that are enriched in the severe patients when comparing to the moderate and control groups. The blue and the red colors show the specific microbial groups that are enriched in the microbiome for moderate and control patients, respectively. Due to the fact that LEfSe includes biologically informative clades differentiating two or more phenotypes, this may be important for clinical therapeutics. On a family level we see that $S 24+7$ and Odoribacteraceae are associated with severe RSV, while Clostridiales and Lactobacillaceae are characteristic of moderate RSV (Fig. 4a). At the genus level, we observed S24_7, Odoribacter, and Oribacterium being associated with severe RSV and Clostridiales and Coriobacteriaceae being associated with moderate disease (Fig. 4b). The specific microbes associated with genus and OTUs are also shown in Fig. 4c. Furthermore, we used discriminant analysis of principal components at the OTU level in conjunction with one-way ANOVA with Benjamini-Hochberg correction and Tukey's range test to further elucidate the microbial differences between disease severity groups. We showed that specific OTUs belonging to the Enterococcus, Lactobacillus,

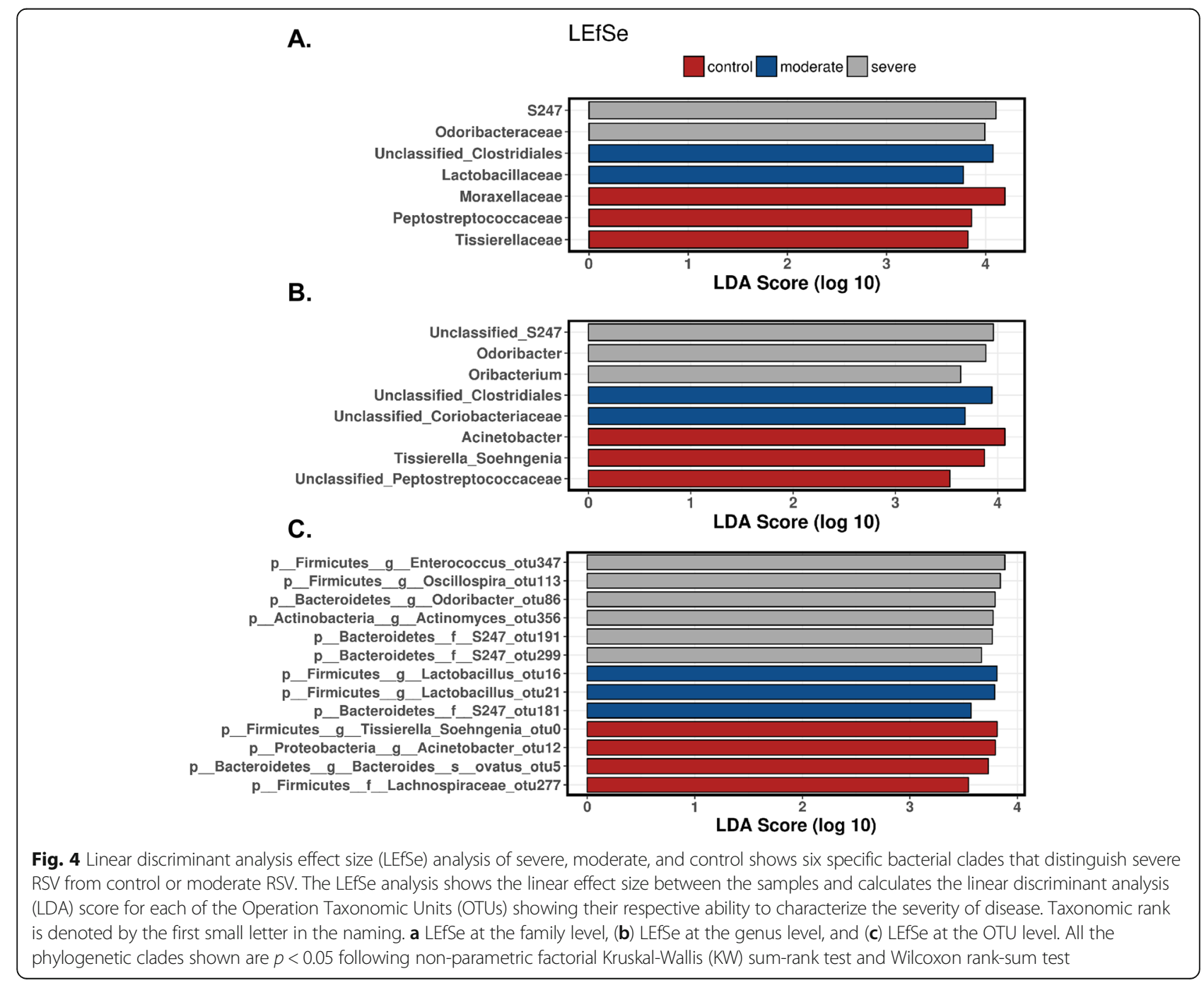


Oscillospira, Odoribacter, Tissierella Soehngenia, and S24_7 families were among the top bacterial taxa to separate the specific microbiome characteristics between the groups in a discriminant analysis of principal components (DAPC) cluster graph (Fig. 5a). DAPC analysis utilizes sequential K-means and model selection to infer genetic clusters by focusing on between-group variability and identifying the variables that best separate these groups. This is further demonstrated by looking at the disease severity groups at the Family level. By inspecting the percent abundance of the families demonstrated to separate the disease severity groups, $S 24+7$ is increased in severe patients compared to control patients while Moraxellaceae is decreased (Fig. 5b). At the genus level, S24_7 is again increased in severe patients compared to control patients while Tissierella Soehngenia is decreased (Fig. 5c). At the OTU level, we observed an increase in relative percent abundance of $S 24+7$ and Odoribacter with a decrease in Tissierella Soehngenia, between severe and control RSV (Fig. 5d). However, the most significant of these was

A.

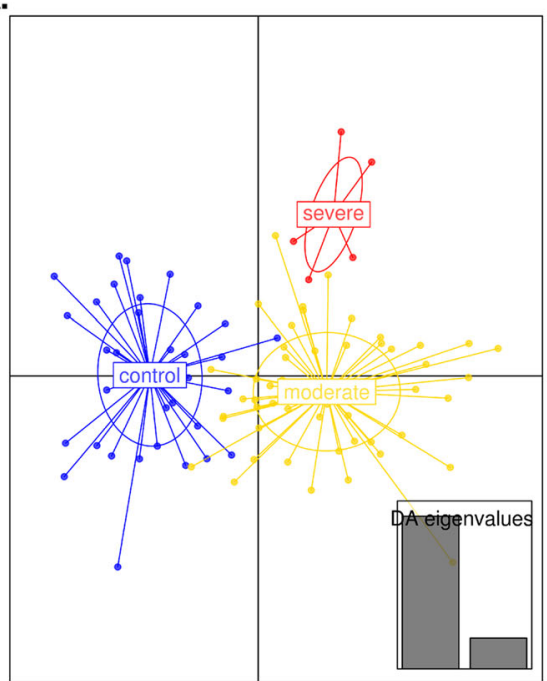

B.

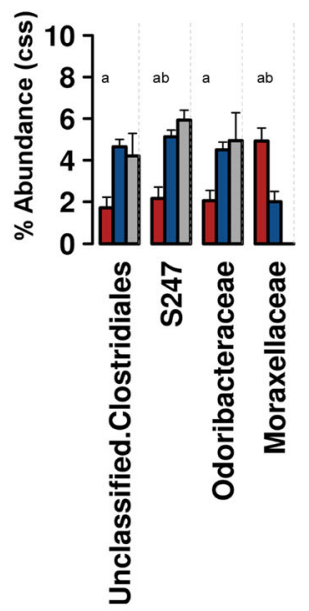

C.

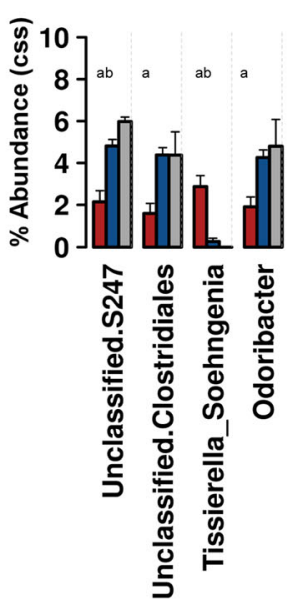

Loading plot

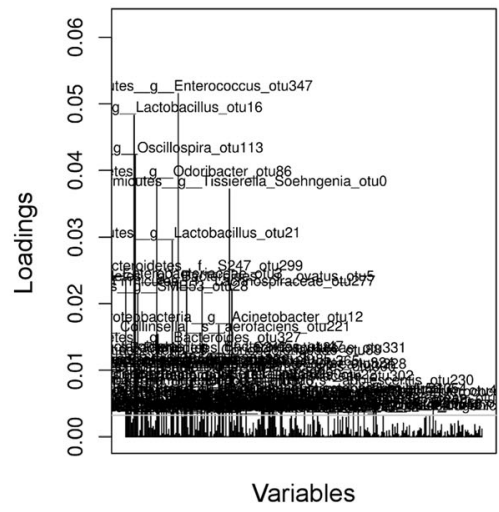

D.

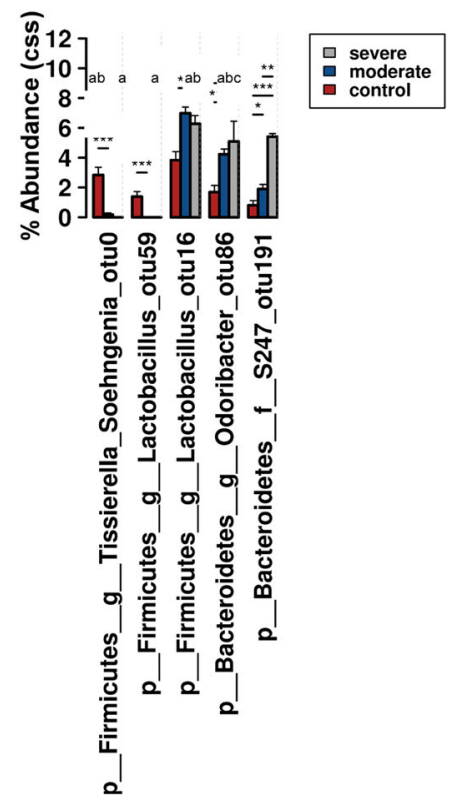

Fig. 5 Discriminant analysis of principal components (DAPC) plot (a) at OTU level revealed distinct clustering of severe patients (red), moderate patients (yellow), and control patients (blue). Canonical loading plot stresses the specific OTUs most influential in the separation of clusters. $\mathbf{b}$ Percent abundance with cumulative-sum scaling (CSS) + log transformation at the family level. c Percent abundance with CSS + log transformation at the genus level. d Percent abundance with CSS + log transformation at the OTU level. Significance $(p<0.05)$ with BH correction between control vs. moderate, control vs. severe, and moderate vs. severe is denoted by a, b, and c, respectively 
significant increases in $S 24+7$ in severe patients compared to moderate patients. This coincides with the LEfSe analysis, giving additional data showing that there is an association with S24_7 and severity of RSV disease.

\section{Discussion}

The lung and gut microbiome axis has increasingly been studied over the last decade to elucidate the relationship between microbiome dysbiosis and immunity in the lung [16-22]. The gut-lung microbiome axis has been proposed and studied for its ability to help regulate the immune system $[13,22,23]$. Because there are a vast number of microbes residing in the gut, there is no shortage of microorganism-associated molecular patterns (MAMPs) as well as pathogen-associated molecular patterns (PAMPs) that can initiate in the gut and alter immune functions in the lung [24]. MAMPs and PAMPS are able to activate Toll Like Receptors (TLR) on dendritic cells, T cells, epithelial cells, macrophages, and B cells. This activation of TLRs can change cytokine, chemokine, and antibody production in the lung, all of which have been shown to be important in viral clearance for RSV [25, 26]. Studies have shown associations between bronchiolitis and the gut microbiome in infants, along with associations between RSV and the gut microbiome of mice. In infants, these studies demonstrated that there was a Bacteroidesdominant profile that was associated with a higher likelihood of bronchiolitis [27]. In mice, there was a significant increase in Bacteroidetes and a decrease in Firmicutes phyla abundance [13]. However, to our knowledge, our study is the first to directly investigate the role of gut microbiota in RSV disease severity in infants. Our findings indicate that between RSV infected patients and control patients there are no significant changes in the abundance of microbes in the gut (Fig. 2a, b), but there is a significant change in gut microbial composition between RSV infected patients and control patients (Fig. 3a).

We observed significant enrichments in the families S24_7, Clostridiales, Odoribacteraceae, Lactobacillaceae, Actinomyces using LEfSe and ANOVA with BH correction between these RSV and control patients. Likewise, our data indicates that when looking at severity (PICU vs. NonPICU vs. Control), there is only a slight decrease in commensal microbial abundance across the patient groups (Fig. 2c, d). We do, however, see separate phylogenetic clustering between the severe and moderate patients and separation from the control patients (Fig. 3b). This clustering was shown to be dependent upon Enterococcus, Lactobacillus, Oscillospira, Odoribacter, Tissierella Soehngenia, and S24_7 (Fig. 4). The LEfSe analysis showed us 6 bacterial OTUs that were enriched in the severe group when compared to the moderate and control groups. Specifically, a significant increase in S24_7 OTU 191 coincided with severe versus moderate RSV (Fig. 5d). This data suggests that the bacteria that are driving these differences are encompassed within the Firmicutes and Bacteroidetes phylum but are varied at the family and OTU levels illustrating unknown factors contributing to this dysbiosis of the gut microbiome. Our study demonstrates that the gut microbiome diversification is associated with RSV disease severity and suggests that altering the gut microbiome may have clinical relevance.

Despite the fact that S24_7 (aka Muribaculaceae or Candidatus Homeothermaceae) has been shown to make up a significant portion of the mouse and human intestinal microbiome, there have been very few studies investigating its role in immunity $[13,28,29]$. One study characterizing 30 population genomes of $S 24+7$ found that 20 of the 30 populations' genomes contain a metalloprotease belonging to M6 peptidase family. Peptidases within this family exhibit antimicrobial capabilities as well as degradation abilities for extracellular matrices (ECM). In addition to M6 peptidase in their genomes, 11 of the 30 populations of $S 24+7$ contained IgA degrading peptidase sequences in their genomes (peptidase family M64). This could be crucial to the microbiome's interaction with RSV severity as it has been shown that IgA is vital for mucosal defense in RSV infection and aids in protection to upper respiratory tract infections [30-34]. These mucosal antibodies have, similarly, been shown to protect human adults from experimental RSV infection [30, 35]. Therefore, IgA is important for protection and disruption of memory IgA can contribute to severity and reoccurrence of RSV.

However, S24_7 is not the only potential mechanism for IgA disruption originating in the gut microbiome. The gut microbiome consists of thousands of commensal bacteria, all of which, play an essential role in immune response and development at an early age. The gut microbiome produces several metabolites that enter the intestinal lymphatic system allowing commensal bacteria in the gut to modulate activation of B cells, dendritic cells [36], inflammatory cytokines, and production of antibodies. Work in adult germ-free mice have demonstrated that a lack of commensal bacteria inhabiting the gut leads to fewer intraepithelial lymphocytes, smaller peyer's patches [37], fewer Th17 T cells [38], and defective regulatory $\mathrm{T}$ cells [39]. In addition, human gut bacteria such as Bacteroides fragilis have been shown to regulate the balance between Th1 and Th2 cells in the lung by producing polysaccharide $\mathrm{A}$ and inducing INF-y (Th1 T cells) [40]. While Clostridium and Clostridiales have been shown to induce regulatory $\mathrm{T}$ cell (Treg) production [41]. In RSV infected patients, we observed increases in the Clostridiales family suggesting an induction of Tregs which are essential in the management of RSV severity. As RSV evades the adaptive immune response by skewing the Th1/Th2 balances 
toward a Th2 specific immune response, the balance between Th1, Th2, and Treg cells are crucial to the pathogenesis of RSV by reducing Th2 immune responses and pulmonary eosinophilia [42]. Therefore, the microbiome dysbiosis that we observe could be a source for T cell imbalance and severe RSV disease. While it is enticing to speculate that elevations in M6 peptidases due to enrichment of S24_7 family members leads to degradation of RSV specific IgA and disease severity, it is yet to be determined whether a gut microbial profile low in diversity and enriched in S24_7 is the cause, or result, of severe RSV disease. Mechanistic studies need to be done in order to address this important question. It is possible that by elucidating the mechanism of S24_7 in RSV disease severity therapeutic targets could be identified.

Our findings highlight that there is a correlation between RSV infection and dysbiosis of the gut microbiome. We identified disruptions in the abundance of microbes in patients with severe RSV disease as well as characteristic microbiome shifts in all RSV patients. We identified that there were 6 specific, enriched microbes associated with RSV severity. Together, our findings identified changes in phylogenetic diversity in RSV patients and identified specific microbes associated with severity of disease. However, there were limitations to this study. One of the limitations of this study is the small sample size, particularly for severe RSV patients. It is also noteworthy that this study was conducted in Memphis, Tennessee where there is a socioeconomic and racial skew in patient demographics that can be a limitation to the extrapolation of these studies across sites. It is unclear if the changes in gut microbiota are causal or correlated with RSV (or hospitalization). Further studies need to be done to characterize the change in gut microbiota of RSV patients fully. Future work will include additional patient recruitment to more precisely define a gut microbial profile associated with severe RSV disease. These studies could lead to the development of logistic regression models to predict infants at high risk for severe RSV disease based on gut microbiome.

\section{Conclusions}

Respiratory syncytial virus (RSV) is a ubiquitous respiratory virus infecting the majority of the human population by 1 year of age. It is the number one cause of lower respiratory tract infections in infants, yet there are still no vaccines or specific antiviral therapies against RSV. Most patients infected with RSV develop mild upper respiratory tract infections, but a percentage of patients develop severe lower respiratory tract infections eliciting the need for intensive care and sometimes resulting in death. While there have been papers that show the interrelationships between gut and nasal microbiome changes in RSV patients there has been no data that observes the relationship between gut microbiota and severity of RSV disease. This manuscript makes the case that gut microbiome changes are associated with severity of RSV disease and these changes could be used to identify therapeutic targets or as biomarkers of severe clinical RSV. The specific interaction of the gut microbiome and respiratory immunity against RSV infections should be investigated in further studies.

\section{Methods}

\section{Ethics statement}

These studies were approved by the Institutional Review Board at the University of Tennessee Health Science Center and Louisiana State University.

\section{Patient enrollment and sample collection}

Patients were enrolled at Le Bonheur Children's Hospital in Memphis, Tennessee, during the RSV season in the years 2014-2016. A total of 58 infants hospitalized with RSV were enrolled in the study (Table 1). This work includes samples from 23 patients that were used in a study recently submitted for publication and 33 patients used in another study recently accepted for publication [43]. Inclusion criteria were patients less than 12 months old (1 control patient was 368 days old), informed consent from parent or guardian, patients could not have a positive blood culture within $72 \mathrm{~h}$ prior to collection of stool, patients could not be diagnosed with any immunodeficiency, patients could not be on any antibiotics within 4 weeks prior to enrollment, patients could not have been placed on oxygen for more than 7 days within 3 months prior to the study, patients could not be receiving other investigational immunomodulatory or investigational antiviral agents, patients could not have a hemodynamically significant congenital heart disease, and patients must have tested positive for RSV and negative for influenza, by RTPCR or be positive for RSV antigens tested by the hospital's diagnostic lab. Among RSV positive patients, 5 infants were admitted to the PICU and thus considered severe; 53 were admitted to the pediatric ward and considered moderate. Healthy controls patients were enrolled from Le Bonheur Outpatient Clinic during well-baby checkups. Within $72 \mathrm{~h}$ of admission to the hospital, stool samples from these infants were collected, and $100 \mathrm{mg}$ aliquots of stool were stored at $-80^{\circ} \mathrm{C}$ until DNA extraction.

\section{$16 \mathrm{~S}$ sequencing}

Fecal DNA was isolated from the $100 \mathrm{mg}$ aliquots of stool using QIAamp PowerFecal DNA Kit (Qiagen) according to the manufacturer's instructions. Fecal DNA was sent to the University of Alabama at Birmingham Center for Clinical and Translational Science for $16 \mathrm{~S}$ sequencing. Unique barcoded primers were used to amplify the hypervariable V4 regions of the bacterial $16 \mathrm{~S}$ rRNA gene from each sample. The resulting amplicon libraries were then gel purified using QIAquick Gel 
Extraction Kit (Qiagen). Finally, the purified libraries were sequenced using Next-generation sequencing performed on the Illumina MiSeq system using $250 \mathrm{bp}$ paired-end reads (Fig. 1a). All generation of amplicon libraries and sample preparation for loadings onto the Illumina MiSeq system protocols were previously published by Kumar et al. [44]

\section{Bioinformatics}

Sequence data with a minimum length of 250 base pairs were processed and analyzed using QIIME 2 version 2018.4.0 (RRID: SCR_008249). Sequences were demultiplexed using Qiime 2 demux, passed through quality control using the deblur quality control method, and created the phylogenetic tree using mafft program to perform a multiple sequence alignment of the sequences and FastTree to create an unrooted tree. The operational taxonomic units (OTUs) were generated using a 99\% identity and then classified by phylogeny using the classifier from GreenGenes database 13_8 [45, 46]. Subsequently, alpha diversity measured using Shannon Index and Chaol Index in Qiime2, beta diversity, the community similarity, measured via unweighted and weighted unifrac distance matrix and PERMANOVA with 999 permutations was used to identify significant features between groups. Linear discriminant analysis effect size (LEfSe: RRID: SCR_014609) in Galaxy (Fig. 1b) was used to discover biomarkers specific to each of the patient groups. In Calypso, the data was normalized using cumulative sum scaling (CSS) normalization for multivariate tests. In order to address false discovery rate two-way repeated-measures analysis of variance (ANOVA) in conjunction with Benjamini-Hochberg multiple-inference correction with Dunnett's correction was used to test for significant differences in alpha diversity and differential taxa abundance between groups. Significance was defined as $p<0.05$ after FDR adjustment (Prism v8.0, GraphPad Software, La Jolla, CA) (Calypso). Quality control of sample data can be found in (Supplemental Figure 1). Data are presented as means \pm SEM. The datasets generated for this study can be found in the SRA accession database: PRJNA579491.

\section{Supplementary information}

Supplementary information accompanies this paper at https://doi.org/10. 1186/s12866-020-01816-5.

Additional file 1: Figure S1. Quality control plots (A) rarefaction analysis showing adequate reads for OTUs. (B) reads per sample showing high read counts for all samples used.

Additional file 2: Figure S2. Bar chart illustrating the microbial abundance differences between the control, moderate, and severe patients at the (A) family level, (B) genus level, and (C) OTU level.

Additional file 3: Figure S3. Odds ratio showing the top 100 biomarkers associated with all RSV patients compared to control patients.

\section{Abbreviations}

RSV: Respiratory syncytial virus; URTI: Upper respiratory tract infections;

LRTI: Lower respiratory tract infections; PICU: Pediatric intensive care unit;

OTU: Operational taxonomic units; LEfSe: Linear discriminant analysis effect size; LDA: Linear discriminant analysis; CSS: Cumulative sum scaling; RDA: Redundant discriminant analysis; DAPC: Discriminant analysis of principal components; PAMP: Pathogen-associated molecular patterns; TLR: Toll Like Receptors

\section{Acknowledgments}

We would like to thank the patients and their families for making this study possible. We also thank Lisa Harrison, Beth Meals, Jackie Blanch, and Tyan Tomlinson for patient enrollment and clinical data collection. Portions of this research were conducted with high performance computing resources provided by Louisiana State University (http://www.hpc.Isu.edu).

\section{Authors' contributions}

DY designed the study. JH executed data management, performed data analyses, and drafted the manuscript. DS enrolled patients and collected clinical data, performed sample processing, and performed data collection. LV performed data collection. JP performed data analysis and drafted the manuscript. JD enrolled patients and collected clinical data. SAC conceptualized and designed the study and drafted the manuscript. All authors approved the final manuscript as submitted and agree to be accountable for all aspects of the work.

\section{Funding}

This work was supported by a grant to D.Y. from the University of Tennessee Health Science Center and Institute for Research, Innovation, Synergy and Health Equity (iRISE), and National Institutes of Health grants (R01Al090059 and R01ES015050) to S.A.C. The funders had no role in study design, data collection, and interpretation, or the decision to submit the work for publication.

\section{Availability of data and materials}

The datasets generated for this study can be found in the SRA accession database: PRJNA579491. https://www.ncbi.nlm.nih.gov/Traces/study/?acc= PRJNA579491\&O=acc_S\%3Aa

\section{Ethics approval and consent to participate}

These studies were approved by the Institutional Review Board at the University of Tennessee Health Science Center and Louisiana State University. Written consent was obtained from the parent(s)/guardian(s) of the patients.

Consent for publication

Not applicable.

\section{Competing interests}

The authors declare that they have no competing interests.

\section{Author details}

'Department of Biological Sciences, Louisiana State University, 202 Life Sciences Building, Baton Rouge, LA 70803, USA. ${ }^{2}$ Department of Comparative Biomedical Sciences, Louisiana State University School of Veterinary Medicine, Baton Rouge, LA, USA. ${ }^{3}$ Department of Pediatrics, University of Tennessee Health Science Center, Memphis, TN, USA. ${ }^{4}$ Le Bonheur Children's Foundation Research Center, Memphis, TN, USA.

Received: 4 February 2020 Accepted: 7 May 2020

Published online: 01 June 2020

\section{References}

1. Glezen WP, Taber LH, Frank AL, Kasel JA. Risk of primary infection and reinfection with respiratory syncytial virus. Am J Dis Child. 1986;140:543-6.

2. Centers for Disease Control and Prevention. Respiratory syncytial virus infection (RSV). 2018.

3. Nair H, Nokes DJ, Gessner BD, Dherani M, Madhi SA, Singleton RJ, O'Brien KL, Roca A, Wright PF, Bruce N, Chandran A, Theodoratou E, Sutanto A, Sedyaningsih ER, Ngama M, Munywoki PK, Kartasasmita C, Simoes EA, Rudan I, Weber MW, Campbell H. Global burden of acute lower respiratory 
infections due to respiratory syncytial virus in young children: a systematic review and meta-analysis. Lancet. 2010;375:1545-55.

4. Hall CB, Weinberg GA, Iwane MK, Blumkin AK, Edwards KM, Staat MA, Auinger P, Griffin MR, Poehling KA, Erdman D, Grijalva CG, Zhu Y, Szilagyi P. The burden of respiratory syncytial virus infection in young children. $N$ Engl J Med. 2009;360:588-98.

5. Leader $\mathrm{S}$, Kohlhase K. Recent trends in severe respiratory syncytial virus (RSV) among US infants, 1997 to 2000. J Pediatr. 2003;143:S127-32.

6. Bont L, Checchia PA, Fauroux B, Figueras-Aloy J, Manzoni P, Paes B, Simões EA, Carbonell-Estrany $X$. Defining the epidemiology and burden of severe respiratory syncytial virus infection among infants and children in Western countries. Infect Dis Ther. 2016:5:271-98.

7. Partty A, Kalliomaki M, Salminen S, Isolauri E. Infant distress and development of functional gastrointestinal disorders in childhood: is there a connection? JAMA Pediatr. 2013;167:977-8.

8. Luoto R, Ruuskanen O, Waris M, Kalliomaki M, Salminen S, Isolauri E. Prebiotic and probiotic supplementation prevents rhinovirus infections in preterm infants: a randomized, placebo-controlled trial. J Allergy Clin Immunol. 2014;133:405-13.

9. de Vrese M, Winkler P, Rautenberg P, Harder T, Noah C, Laue C, Ott S, Hampe J, Schreiber S, Heller K, Schrezenmeir J. Effect of Lactobacillus gasseri PA 16/8, Bifidobacterium longum SP 07/3, B. bifidum MF 20/5 on common cold episodes: a double blind, randomized, controlled trial. Clin Nutr. 2005; 24:481-91.

10. Abt MC, Osborne LC, Monticelli LA, Doering TA, Alenghat T, Sonnenberg GF, Paley MA, Antenus M, Williams KL, Erikson J, Wherry EJ, Artis D. Commensal bacteria calibrate the activation threshold of innate antiviral immunity. Immunity. 2012;37:158-70.

11. Ichinohe T, Pang IK, Kumamoto Y, Peaper DR, Ho JH, Murray TS, Iwasaki A. Microbiota regulates immune defense against respiratory tract influenza a virus infection. Proc Natl Acad Sci U S A. 2011;108:5354-9.

12. Maeda N, Nakamura R, Hirose $Y$, Murosaki S, Yamamoto $Y$, Kase T, Yoshikai Y. Oral administration of heat-killed Lactobacillus plantarum L-137 enhances protection against influenza virus infection by stimulation of type I interferon production in mice. Int Immunopharmacol. 2009;9:1122-5.

13. Groves HT, Cuthbertson L, James P, Moffatt MF, Cox MJ, Tregoning JS. Respiratory disease following viral lung infection alters the murine gut microbiota. Front Immunol. 2018:9:182.

14. de Steenhuijsen Piters WA, Heinonen S, Hasrat R, Bunsow E, Smith B, Suarez-Arrabal MC, Chaussabel D, Cohen DM, Sanders EA, Ramilo O, Bogaert D, Mejias A. Nasopharyngeal microbiota, host Transcriptome, and disease severity in children with respiratory syncytial virus infection. Am J Respir Crit Care Med. 2016;194:1104-15.

15. Mansbach JM, Hasegawa K, Henke DM, Ajami NJ, Petrosino JF, Shaw CA, Piedra PA, Sullivan AF, Espinola JA, Camargo CA Jr. Respiratory syncytial virus and rhinovirus severe bronchiolitis are associated with distinct nasopharyngeal microbiota. J Allergy Clin Immunol. 2016;137: 1909-1913.e1904.

16. Roussos A, Koursarakos P, Patsopoulos D, Gerogianni I, Philippou N. Increased prevalence of irritable bowel syndrome in patients with bronchial asthma. Respir Med. 2003;97:75-9.

17. Marsland BJ, Trompette A, Gollwitzer ES. The gut-lung axis in respiratory disease. Ann Am Thorac Soc. 2015;12(Suppl 2):S150-6.

18. Russell SL, Gold MJ, Hartmann M, Willing BP, Thorson L, Wlodarska M, Gill N, Blanchet MR, Mohn WW, McNagny KM, Finlay BB. Early life antibiotic-driven changes in microbiota enhance susceptibility to allergic asthma. EMBO Rep. 2012:13:440-7.

19. Keely S, Talley NJ, Hansbro PM. Pulmonary-intestinal cross-talk in mucosal inflammatory disease. Mucosal Immunol. 2012;5:7-18.

20. Thorburn AN, Foster PS, Gibson PG, Hansbro PM. Components of Streptococcus pneumoniae suppress allergic airways disease and NKT cells by inducing regulatory T cells. J Immunol. 2012;188:4611-20.

21. Budden KF, Gellatly SL, Wood DLA, Cooper MA, Morrison M, Hugenholtz P, Hansbro PM. Emerging pathogenic links between microbiota and the gutlung axis. Nat Rev Microbiol. 2016;15:55.

22. Schuijt TJ, Lankelma JM, Scicluna BP, de Sousa e Melo F, Roelofs JJ, de Boer JD, Hoogendijk AJ, de Beer R, de Vos A, Belzer C, de Vos WM, van der Poll T, Wiersinga WJ. The gut microbiota plays a protective role in the host defence against pneumococcal pneumonia. Gut. 2016;65:575-83.

23. Samuelson DR, Welsh DA, Shellito JE. Regulation of lung immunity and host defense by the intestinal microbiota. Front Microbiol. 2015;6:1085.
24. Ivanov II, Honda K. Intestinal commensal microbes as immune modulators. Cell Host Microbe. 2012;12:496-508.

25. Hijano DR, Siefker DT, Shrestha B, Jaligama S, Vu LD, Tillman H, Finkelstein D, Saravia J, You D, Cormier SA. Type I interferon potentiates IgA immunity to respiratory syncytial virus infection during infancy. Sci Rep. 2018;8:11034.

26. You D, Marr N, Saravia J, Shrestha B, Lee Gl, Turvey SE, Brombacher F, Herbert DR, Cormier SA. IL-4Ralpha on CD4+ T cells plays a pathogenic role in respiratory syncytial virus reinfection in mice infected initially as neonates. J Leukoc Biol. 2013;93:933-42.

27. Hasegawa K, Linnemann RW, Mansbach JM, Ajami NJ, Espinola JA, Petrosino JF, Piedra PA, Stevenson MD, Sullivan AF, Thompson AD, Camargo CA. The fecal microbiota profile and bronchiolitis in infants. Pediatrics. 2016;138: e20160218.

28. Seedorf H, Griffin NW, Ridaura VK, Reyes A, Cheng J, Rey FE, Smith MI, Simon GM, Scheffrahn RH, Woebken D, Spormann AM, Van Treuren W, Ursell LK, Pirrung M, Robbins-Pianka A, Cantarel BL, Lombard V, Henrissat B, Knight R, Gordon JI. Bacteria from diverse habitats colonize and compete in the mouse gut. Cell. 2014;159:253-66.

29. Ormerod KL, Wood DL, Lachner N, Gellatly SL, Daly JN, Parsons JD, Dal'Molin CG, Palfreyman RW, Nielsen LK, Cooper MA, Morrison M, Hansbro PM, Hugenholtz P. Genomic characterization of the uncultured Bacteroidales family S24-7 inhabiting the guts of homeothermic animals. Microbiome. 2016:4:36

30. Bagga B, Cehelsky JE, Vaishnaw A, Wilkinson T, Meyers R, Harrison LM, Roddam PL, Walsh EE, DeVincenzo JP. Effect of preexisting serum and mucosal antibody on experimental respiratory syncytial virus (RSV) challenge and infection of adults. J Infect Dis. 2015;212:1719-25.

31. Hall CB, Walsh EE, Long CE, Schnabel KC. Immunity to and frequency of reinfection with respiratory syncytial virus. J Infect Dis. 1991;163:693-8.

32. Lee FE, Walsh EE, Falsey AR, Betts RF, Treanor JJ. Experimental infection of humans with A2 respiratory syncytial virus. Antivir Res. 2004;63:191-6.

33. Prince GA, Hemming VG, Horswood RL, Baron PA, Chanock RM. Effectiveness of topically administered neutralizing antibodies in experimental immunotherapy of respiratory syncytial virus infection in cotton rats. J Virol. 1987;61:1851-4.

34. Siber GR, Leombruno D, Leszczynski J, Mclver J, Bodkin D, Gonin R, Thompson CM, Walsh EE, Piedra PA, Hemming VG, et al. Comparison of antibody concentrations and protective activity of respiratory syncytial virus immune globulin and conventional immune globulin. J Infect Dis. 1994;169:1368-73.

35. Habibi MS, Jozwik A, Makris S, Dunning J, Paras A, DeVincenzo JP, de Haan CAM, Wrammert J, Openshaw PJM, Chiu C, Mechanisms of Severe Acute Influenza Consortium I. Impaired antibody-mediated protection and defective IgA B-cell memory in experimental infection of adults with respiratory syncytial virus. Am J Respir Crit Care Med. 2015;191:1040-9.

36. Chauvistré H, Küstermann C, Rehage N, Klisch T, Mitzka S, Felker P, RoseJohn S, Zenke M, Seré KM. Dendritic cell development requires histone deacetylase activity. Eur J Immunol. 2014;44:2478-88.

37. Mazmanian SK, Liu CH, Tzianabos AO, Kasper DL. An immunomodulatory molecule of symbiotic bacteria directs maturation of the host immune system. Cell. 2005;122:107-18.

38. Ivanov II, Atarashi K, Manel N, Brodie EL, Shima T, Karaoz U, Wei D, Goldfarb KC, Santee CA, Lynch SV, Tanoue T, Imaoka A, Itoh K, Takeda K, Umesaki Y, Honda K, Littman DR. Induction of intestinal Th17 cells by segmented filamentous bacteria. Cell. 2009;139:485-98.

39. Zeng $\mathrm{H}$, Chi $\mathrm{H}$. Metabolic control of regulatory $\mathrm{T}$ cell development and function. Trends Immunol. 2015;36:3-12.

40. Vael C, Nelen V, Verhulst SL, Goossens H, Desager KN. Early intestinal Bacteroides fragilis colonisation and development of asthma. BMC Pulm Med. 2008:8:19.

41. Atarashi K, Tanoue T, Shima T, Imaoka A, Kuwahara T, Momose Y, Cheng G, Yamasaki S, Saito T, Ohba Y, Taniguchi T, Takeda K, Hori S, Ivanov II, Umesaki Y, Itoh K, Honda K. Induction of colonic regulatory T cells by indigenous Clostridium species. Science. 2011;331:337-41.

42. Becker Y. Respiratory syncytial virus (RSV) evades the human adaptive immune system by skewing the Th1/Th2 cytokine balance toward increased levels of Th2 cytokines and lgE, markers of allergy--a review. Virus Genes. 2006;33:235-52.

43. Vu LD, Siefker D, Jones TL, You D, Taylor R, DeVincenzo J, Cormier SA. Elevated levels of type 2 respiratory innate lymphoid cells in human infants with severe RSV bronchiolitis. Am J Respir Crit Care Med. 2019;200: 1414-23. 
44. Kumar R, Eipers P, Little RB, Crowley M, Crossman DK, Lefkowitz EJ, Morrow CD. Getting started with microbiome analysis: sample acquisition to bioinformatics. Curr Protoc Hum Genet. 2014;82:18.18.11-29.

45. Yildiz S, Mazel-Sanchez B, Kandasamy M, Manicassamy B, Schmolke M Influenza a virus infection impacts systemic microbiota dynamics and causes quantitative enteric dysbiosis. Microbiome. 2018;6:9.

46. Round JL, Mazmanian SK. The gut microbiota shapes intestinal immune responses during health and disease. Nat Rev Immunol. 2009;9:313-23.

\section{Publisher's Note}

Springer Nature remains neutral with regard to jurisdictional claims in published maps and institutional affiliations.

Ready to submit your research? Choose BMC and benefit from:

- fast, convenient online submission

- thorough peer review by experienced researchers in your field

- rapid publication on acceptance

- support for research data, including large and complex data types

- gold Open Access which fosters wider collaboration and increased citations

- maximum visibility for your research: over $100 \mathrm{M}$ website views per year

At BMC, research is always in progress.

Learn more biomedcentral.com/submissions 